\title{
COMPARISON BETWEEN OXIDATIVE AND NON-OXIDATIVE TORREFACTION PRETREATMENT AS ALTERNATIVES TO ENHANCE PROPERTIES OF BIOMASS
}

\author{
ANA ÁLVAREZ, INÉS GUTIÉRREZ, CONSUELO PIZARRO, ANTONIO G. LAVÍN \& JULIO L. BUENO \\ Department of Chemical and Environmental Engineering, University of Oviedo, Spain
}

\begin{abstract}
Oxidative and non-oxidative torrefaction pretreatments are the most employed in order to enhance some properties of biomass such as hygroscopicity, low energy density, or poor grindability and so biomass could be a more competitive renewable energy source. The aim of this paper is to compare oxidative and non-oxidative torrefaction processes applying to a pine wood sample. Torrefaction in the range of temperatures $200-250^{\circ} \mathrm{C}$ was conducted in a tube furnace reactor and proximate and ultimate analyses and heating value determination were carried out in order to characterize the torrefied samples. Torrefaction kinetics were obtained at three different temperatures using a thermogravimetric analyser. Both mass and energy yields in oxidative cases were lower as torrefaction temperature was increased compared to non-oxidative treatment. Heating value data of oxidative option were slightly lower than those of non-oxidative one were, although they were higher than the heating value of raw biomass. According to the proximate analysis, the moisture content decreased from $7.63 \%$ in raw biomass to $3.46 \%$ and $3.15 \%$ in pine torrefied at $250^{\circ} \mathrm{C}$ in oxidizing and inert atmospheres, respectively. $\mathrm{H} / \mathrm{C}$ and $\mathrm{O} / \mathrm{C}$ ratios decrease was more drastic for oxidative torrefaction than for non-oxidative one. In addition, the van Krevelen diagram shows that oxidative torrefaction is more interesting than non-oxidative alternative, this circumstance suggests that any optimizing criterion has to take into account at least three variables, including ultimate analysis and mass and energy yields.
\end{abstract}

Keywords: oxidative torrefaction, non-oxidative torrefaction, pine, biomass, torrefaction kinetics.

\section{INTRODUCTION}

Biofuels from renewable biomass has attracted increasing attention as an alternative to substitute fossil fuels [1]. Biomass is the largest renewable energy source, providing $10 \%$ of world primary energy supply [2]. However, some properties of biomass are inconvenient, such as its high oxygen content, low heating value or the hydrophilic behaviour, which may cause problems in its transport, storage and combustion. Furthermore, its fibrous nature causes a difficult grinding, which requires high-energy input.

Dry torrefaction is a mild pyrolysis process carried out at low temperature $\left(200-300{ }^{\circ} \mathrm{C}\right)$ under inert (non-oxidative) or oxidizing (oxidative) atmosphere [3]. Torrefaction offers some solutions for the above problems by reducing the $\mathrm{O} / \mathrm{C}$ ratio of biomass due to the removal of oxygen. As a result, moisture content of biomass drops drastically, energy required for grinding is lower and biomass turns hydrophobic [4]. In addition, high amounts of oxygen results in smoking during combustion [5] and it can be reduced due to the lower oxygen content of torrefied biomass.

Majority of research is focused on non-oxidative torrefaction [1], [4], [6]-[24]. However, the reduction of operating costs is an important issue to practice torrefaction commercially. Oxidative torrefaction could achieve this reduction. Recently, a number of studies related to oxidative torrefaction have been carried out, most of them related with residues from oil palm industry [21]-[26] although, some of them studied the oxidative torrefaction of ligneous biomass such as spruce and fir sawdust [27], eucalyptus [21], [23], [24], [28], pine and beech 
[29]. The common idea of all these articles is that there are few differences between oxidative and non-oxidative torrefaction in ligneous biomass. Meanwhile, mass yield of oxidative torrefaction in fibrous biomass such as oil palm fibre is drastically lower than mass yield of non-oxidative torrefaction. Thus, oxidative torrefaction is only appropriate for ligneous biomass.

Devolatilisation and pyrolysis of biomass are the main mechanisms of thermal degradation in non-oxidative torrefaction. On the other hand, the oxidation of hydrocarbons also affects the decomposition of biomass in oxidative torrefaction [24].

The present study focuses on the oxidative and non-oxidative torrefaction of pine wood. Mass and energy yields and full characterisation of torrefied biomass (proximate and ultimate analyses and high heating value) together with isothermal kinetics of torrefaction at three different temperatures were obtained.

\section{MATERIALS AND METHODS}

\subsection{Sample preparation}

A sample of pine wood was used to study and compare the behaviour of oxidative and nonoxidative torrefaction treatments as commercial biomass such as pellets are made mainly of pine wood. The sample was grinded and sieved to a size between $710-1000 \mu \mathrm{m}$ and the characterization of the raw biomass sample was conducted (Table 1).

\subsection{Torrefaction experiments}

Torrefaction processes were carried out in a MTF 12/38/150 tube furnace reactor (Carbolite) at three different temperatures $\left(200,225\right.$ and $\left.250^{\circ} \mathrm{C}\right)$. Nitrogen and air were used in nonoxidative and oxidative torrefaction, respectively. The temperature of the reactor was raised to the selected temperature and held for 20 min at that temperature meanwhile a constant $\mathrm{N}_{2}$ or air flux of $1 \mathrm{~L} / \mathrm{min}$ as the inert and oxidative gas, respectively.

Table 1: Characterization of raw biomass sample.

\begin{tabular}{|c|c|}
\hline & Pine \\
\hline \multicolumn{2}{|c|}{ Proximate analysis, \% } \\
\hline Moisture & 7.63 \\
\hline Volatiles & 87.87 \\
\hline Ash & 0.25 \\
\hline Fixed Carbon & 4.25 \\
\hline \multicolumn{2}{|c|}{ Ultimate analysis, $\%$} \\
\hline $\mathrm{C}$ & 47.90 \\
\hline $\mathrm{N}$ & 0.16 \\
\hline $\mathrm{S}$ & 0.51 \\
\hline $\mathrm{H}$ & 6.53 \\
\hline $\mathrm{O}$ & 44.89 \\
\hline $\mathrm{HHV}, \mathrm{J} / \mathrm{g}$ & 19402 \\
\hline
\end{tabular}




\subsection{Analysis of torrefied biomass}

Proximate and ultimate analysis and heating value determination were performed on torrefied samples. Proximate analysis was performed in a CWF 11/13 muffle furnace (Carbolite) following ASTM standards [30]-[32] and higher heating value was determined using a C5000 calorimetric bomb (IKA Werke) following the ASTM E711 standard [33]. The ultimate analysis was obtained using a Vario Macro CHNS elemental analyser (Elementar). The weight percent of carbon, hydrogen, nitrogen and sulphur in samples can be detected simultaneously, while the weight percent of oxygen was determined by difference.

\subsection{Kinetics of torrefaction and combustion}

$4 \mathrm{mg}$ of the sample were subjected to thermal decomposition at three different temperatures 200,225 and $250^{\circ} \mathrm{C}$ to study the torrefaction kinetics. Both types of experiments were conducted in a STA 6000 thermogravimetric analyser (Perkin Elmer). Inert atmosphere for non-oxidative torrefaction kinetics was achieved using $200 \mathrm{ml} / \mathrm{min}$ of nitrogen as carrier gas [4], while for oxidising atmosphere option $40 \mathrm{ml} / \mathrm{min}$ of air as carrier gas was employed [34]. The temperature program described by Chen and Kuo [4], was used to obtain the kinetic parameter of both types of torrefaction.

\section{RESULTS AND DISCUSSION}

\subsection{Mass and energy yields}

The mass yield is an indicator of how biomass resists to thermal degradation. The mass yield of pine wood subjected to both non-oxidative (N-Ox) and oxidative (Ox) torrefaction process were in the range $91.84-85.57 \%$ and $96.67-84.34 \%$ for non-oxidative and oxidative torrefaction, respectively (Fig. 1). Oxidative torrefaction shows lower mass yield than nonoxidative option, though the difference is minimal. The energy yield decays deeper in oxidative torrefaction than in non-oxidative option with values in the range 95.49-87.19\% and $96.36-93.18 \%$ for oxidative and non-oxidative torrefaction respectively (Fig. 2). It is widely accepted that the optimal balance of mass and energy yields for biomass torrefaction is $80 \%$ of mass yield and $90 \%$ of energy yield in the torrefied biomass [1], [35], [36]. Consequently, both types of torrefaction could be appropriate for pine if the changes in its hygroscopic behaviour are those that are required to enhance the characteristics of biomass as a solid fuel.

\subsection{Proximate and elemental analyses}

The proximate analysis (Fig. 3) shows a decrease in the moisture content as the torrefaction temperature increases. The hydrophobic behaviour of torrefied biomass seems to be stronger when biomass is subjected to non-oxidative torrefaction since the percentage of moisture is lower in biomass torrefied under non-oxidative conditions. In Fig. 3, there is a general trend of decreasing volatile matter and increasing fixed carbon content as the torrefaction conditions become more severe. It means that the reactivity of the torrefied biomass is lower and its heating value higher as the temperature of torrefaction increases. The van Krevelen diagram shows the decrease of both atomic ratios $\mathrm{O} / \mathrm{C}$ and $\mathrm{H} / \mathrm{C}$ as the torrefaction temperature increases (Fig. 4). The comparison between both types of torrefaction suggests that presence of oxygen dramatically affects the $\mathrm{H} / \mathrm{C}$ ratio while $\mathrm{O} / \mathrm{C}$ is less affected. The 
explanation of this behaviour is related with the thermal degradations mechanisms of both torrefaction processes as discussed in the introduction.

Figure 1: Relationship between mass yield and torrefaction temperature.
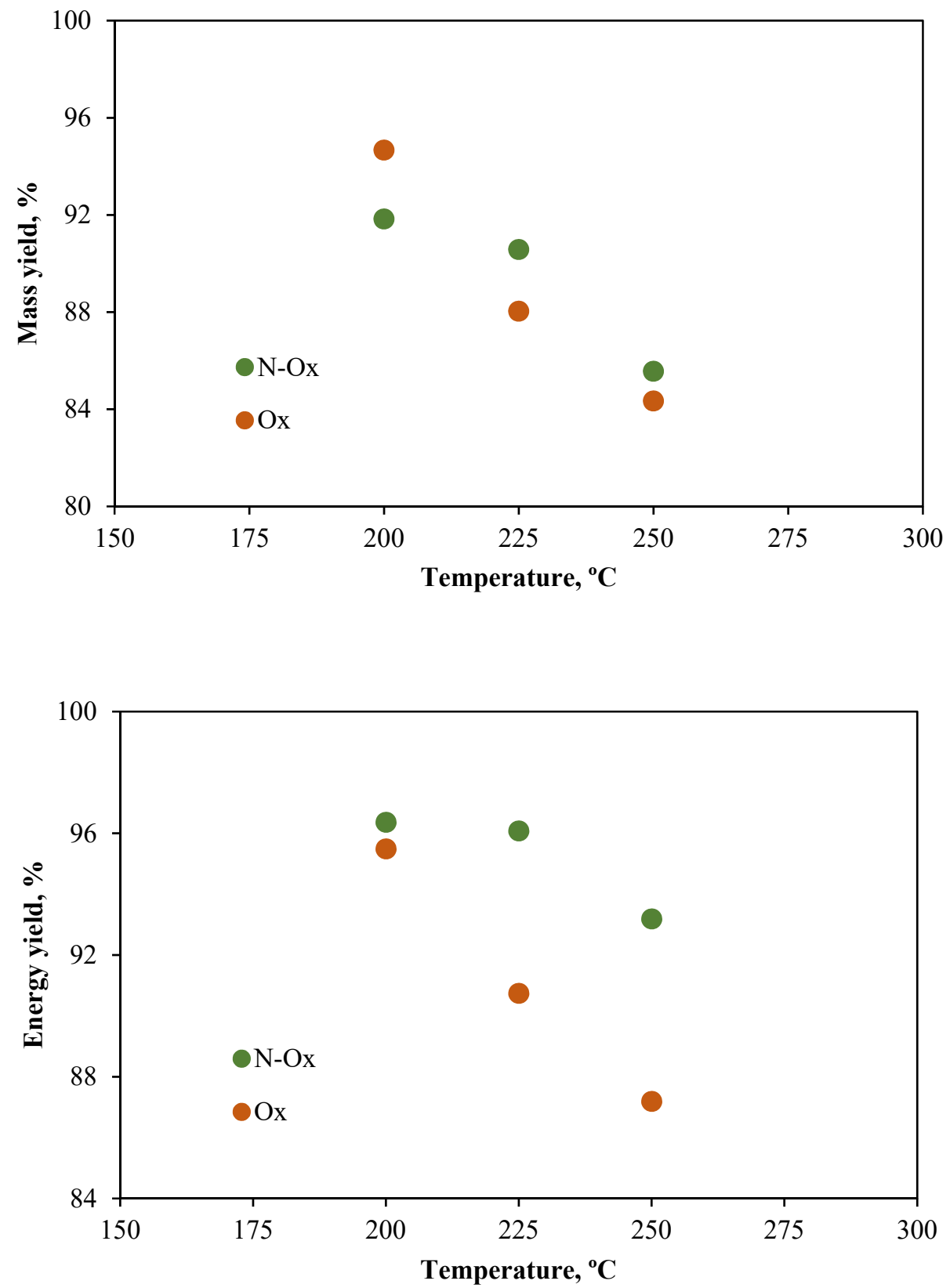

Figure 2: Relationship between energy yield and torrefaction temperature. 


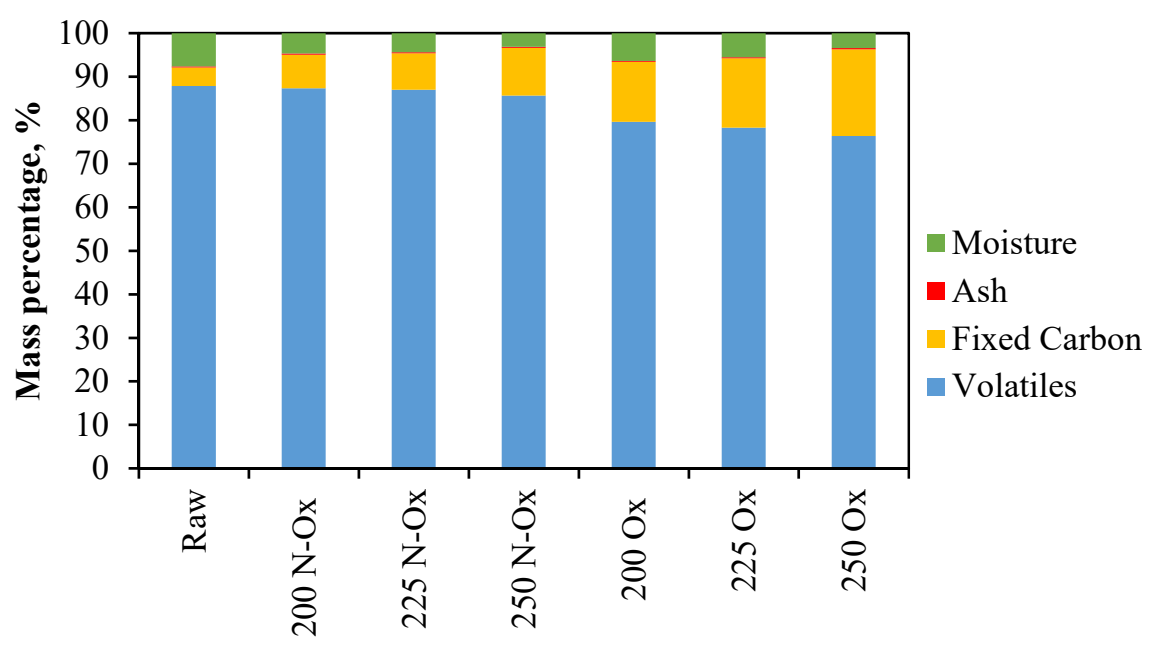

Figure 3: Proximate analysis for all the torrefaction conditions.

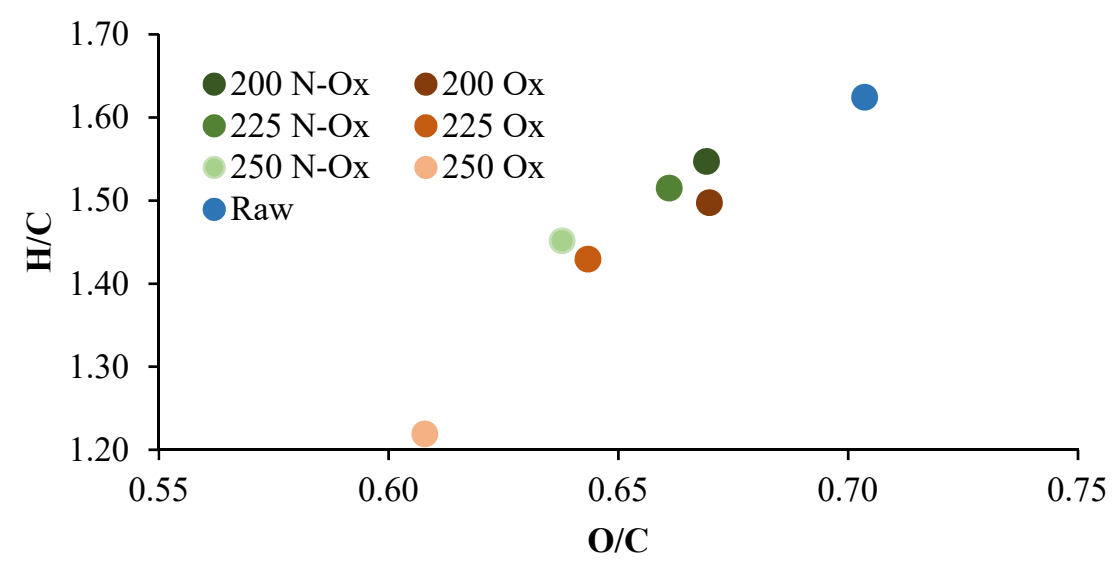

Figure 4: Van Krevelen diagram of non-oxidative and oxidative torrefaction processes.

\subsection{Kinetics of torrefaction}

Isothermal kinetics can be obtained easily as torrefaction is an isothermal process. The conversion-time relationship of a sample is given by eqn (1).

$$
\frac{d \alpha}{d t}=k(1-\alpha)^{n},
$$

where the conversion of the sample, $\alpha$, is defined by eqn (2).

$$
\alpha=\frac{W_{i}-W}{W_{i}-W_{f}}
$$


where $\mathrm{W}_{\mathrm{i}}$ and $\mathrm{W}_{\mathrm{f}}$ are the initial $\left(105^{\circ} \mathrm{C}\right)$ and final $\left(800^{\circ} \mathrm{C}\right)$ weights of the sample respectively, while $\mathrm{W}$ is the weight of the sample at time $\mathrm{t}$.

If the order of reaction is unity, the integration of eqn (1) gives eqn (3).

$$
\ln \left(\frac{1-\alpha_{0}}{1-\alpha}\right)=k\left(t-t_{0}\right)
$$

where $\alpha_{0}$ is the conversion of the sample at the beginning of torrefaction where $t=t_{0}$. If the order of reaction is not unity, the integration of eqn (1) gives eqn (4).

$$
(1-\alpha)^{1-n}-\left(1-\alpha_{0}\right)^{1-n}=k(n-1)\left(t-t_{0}\right) \text {. }
$$

The order of reaction, $\mathrm{n}$, was close to 1.9 for non-oxidative torrefaction and 1.8 for oxidative torrefaction (Table 2). In addition, the rate constant, $\mathrm{k}$, was in the range $1.74 \cdot 10^{-5}$ $4.91 \cdot 10^{-5} \mathrm{~s}^{-1}$. The rate constant was of the same order of magnitude as in the work of Chen and Kuo for hemicellulose [4]. As can be observed in Table 2, there are no significant differences between kinetics parameters of both types of torrefaction.

Simulations of the conversion of the samples during oxidative and non-oxidative torrefaction were evaluated from eqn (5)

$$
\alpha=1-\left[k\left(t-t_{0}\right)(n-1)+\left(1-\alpha_{0}\right)^{1-n}\right]^{\frac{1}{1-n}} .
$$

In order to evaluate the reliability of the torrefaction kinetics, simulations and experimental data are compared (Fig. 5). As shown in Fig. 5, prediction and experimental data are in good agreement in all cases.

\section{CONCLUSIONS}

Mass and energy yields of oxidative torrefaction were lower than those of non-oxidative torrefaction were. Despite this, mass and energy yields of oxidative torrefaction are high enough to consider oxidative torrefaction of pine as a feasible option and cheaper than nonoxidative torrefaction.

Decrease of the amount of oxygen was achieved with both types of torrefaction, but it was even higher in oxidative torrefaction. This leads to less smoking during combustion of torrefied biomass and consequently oxidative torrefaction could be the preferable option.

Table 2: Kinetic parameters of the non-oxidative ( $\mathrm{N}-\mathrm{Ox})$ and oxidative $(\mathrm{Ox})$ torrefaction.

\begin{tabular}{|c|c|c|c|}
\hline Experiment & $\mathrm{n}$ & $\mathrm{k}\left(\mathrm{s}^{-1}\right) \times 10^{5}$ & $\mathrm{R}^{2}$ \\
\hline N-Ox 200 & 2.0 & 1.85 & 0.96 \\
\hline N-Ox 225 & 1.9 & 1.78 & 0.98 \\
\hline N-Ox 250 & 1.9 & 3.94 & 0.990 \\
\hline Ox 200 & 1.8 & 1.74 & 0.996 \\
\hline Ox 225 & 1.8 & 2.58 & 0.995 \\
\hline Ox 250 & 1.8 & 4.91 & 0.995 \\
\hline
\end{tabular}




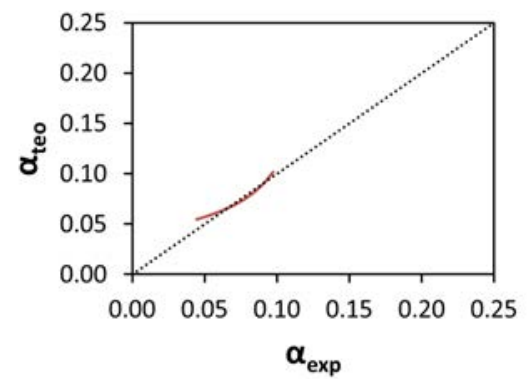

(a)

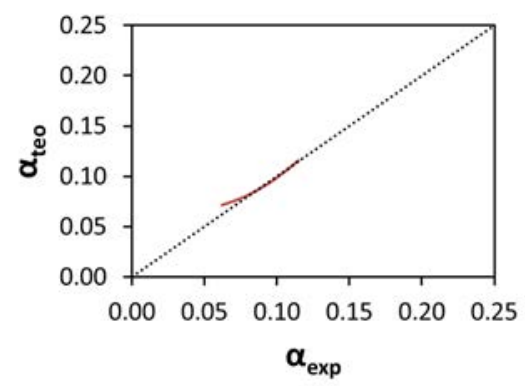

(b)

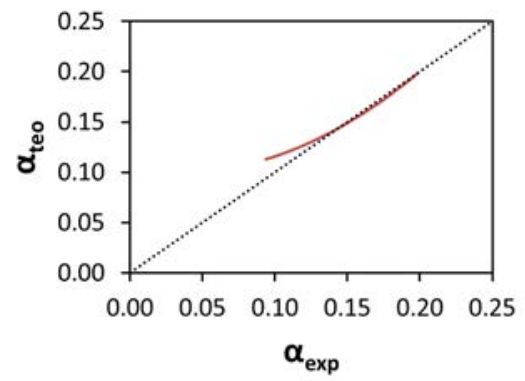

(c)

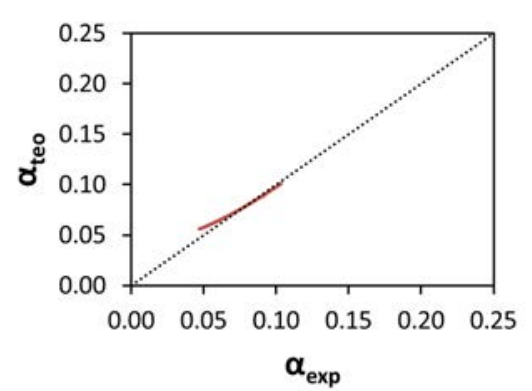

(d)

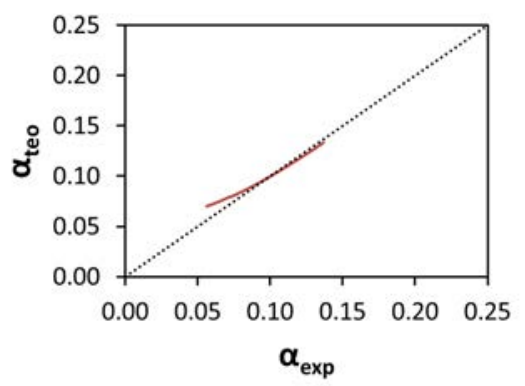

(e)

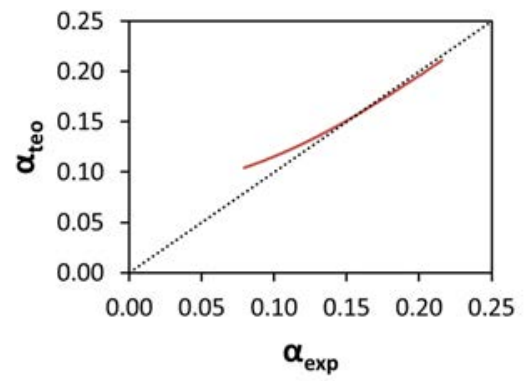

(f)

Figure 5: Comparison between values of predicted and experimental conversion for nonoxidative $(\mathrm{a}, \mathrm{b}$ and $\mathrm{c})$ and oxidative $(\mathrm{d}$, e and $\mathrm{f})$ torrefaction at different temperatures: (a) and (d) $200^{\circ} \mathrm{C}$; (b) and (e) $225^{\circ} \mathrm{C}$; (c) and (f) $250^{\circ} \mathrm{C}$.

Moisture of oxidatively torrefied biomass was higher than non-oxidatively torrefied biomass, but the differences were minimal and, therefore, this factor is not decisive. Furthermore, oxidative torrefaction achieved a higher fixed carbon content than nonoxidative torrefaction.

Regarding kinetic parameters, no significant differences were found between oxidative and non-oxidative torrefaction and the results were close to already published data.

\section{ACKNOWLEDGEMENTS}

This article is greatly indebted to Ministerio de Economía, Industria y Competitividad MINECO (Spain) for the economic support given to the Normalized Vegetable Biomass for 
Efficient Energetic Trigeneration project (MINECO-13-CTQ2013-45155-R) and Consejería de Economía y Empleo del Principado de Asturias for the economic support given to the TRIBIONOR project (PCTI Asturias 2013-2017, Ref. FC-15-GRUPIN14-095), which makes the continuation of research in this field possible. A. Álvarez acknowledges receipt of a graduate fellowship from the Severo Ochoa Program (Principado de Asturias, Spain).

\section{REFERENCES}

[1] Arias, B. et al., Influence of torrefaction on the grindability and reactivity of woody biomass. Fuel Process Technol, 89, pp. 169-175, 2008.

[2] Bioenergyhttps://www.iea.org/topics/renewables/subtopics/bioenergy/ 2011. Accessed on: 4 Aug. 2016.

[3] Chen, W.H., Chapter 10 - Torrefaction. In: Negi S, Binod P, Larroche C (eds) Pretreatment of Biomass. Amsterdam: Elsevier, pp. 173-192.

[4] Chen, W.H. \& Kuo, P.C., Isothermal torrefaction kinetics of hemicellulose, cellulose, lignin and xylan using thermogravimetric analysis. Energy, 36, pp. 6451-6460, 2011.

[5] van der Stelt, M.J.C. et al., Biomass upgrading by torrefaction for the production of biofuels: A review. Biomass Bioenergy, 35, pp. 3748-3762, 2011.

[6] Chen, W.H. \& Kuo, P.C., A study on torrefaction of various biomass materials and its impact on lignocellulosic structure simulated by a thermogravimetry. Energy 35, pp. 2580-2586, 2010.

[7] Chen, W.H., \& Kuo, P.C., Torrefaction and co-torrefaction characterization of hemicellulose, cellulose and lignin as well as torrefaction of some basic constituents in biomass. Energy, 36, pp. 803-811, 2011.

[8] Ibrahim, R.H.H. et al., Physicochemical characterisation of torrefied biomass. J Anal Appl Pyrolysis, 103, pp. 21-30, 2013.

[9] Chiou, B.S. et al., Torrefaction of pomaces and nut shells. Bioresour Technol; 177, pp. 58-65, 2015.

[10] Matali, S. et al., Lignocellulosic Biomass Solid Fuel Properties Enhancement via Torrefaction. Procedia Eng, 148, pp. 671-678, 2016.

[11] Phanphanich, M. \& Mani, S., Impact of torrefaction on the grindability and fuel characteristics of forest biomass. Bioresour Technol, 102, pp. 1246-1253, 2011.

[12] Prins, M.J., Ptasinski, K.J. \& Janssen, F., Torrefaction of wood - Part 2. Analysis of products. J Anal Appl Pyrolysis; 77, pp. 35-40, 2006.

[13] Strandberg, M. et al., Effects of temperature and residence time on continuous torrefaction of spruce wood. Fuel Process Technol, 134, pp. 387-398, 2015.

[14] Gil, M.V. et al., Grindability and combustion behavior of coal and torrefied biomass blends. Bioresour Technol, 191, pp. 205-212, 2015.

[15] Almeida, G., Brito, J.O. \& Perré, P., Alterations in energy properties of eucalyptus wood and bark subjected to torrefaction: The potential of mass loss as a synthetic indicator. Bioresour Technol, 101, pp. 9778-9784, 2010.

[16] Arteaga-Pérez, L.E. et al., Torrefaction of Pinus radiata and Eucalyptus globulus: A combined experimental and modeling approach to process synthesis. Energy Sustain Dev, 29, pp. 13-23, 2015.

[17] Arteaga-Pérez, L.E. et al., Torrefaction of wood and bark from Eucalyptus globulus and Eucalyptus nitens: Focus on volatile evolution vs feasible temperatures. Energy, 93, Part 2, pp. 1731-1741, 2015.

[18] Chen, W.H., et al., Thermal characterization of oil palm fiber and eucalyptus in torrefaction. Energy, 71, pp. 40-48. 2014. 
[19] Nachenius, R.W. et al., Torrefaction of pine in a bench-scale screw conveyor reactor. Biomass Bioenergy 79, pp. 96-104, 2015.

[20] Martín-Lara, M.A. et al., Torrefaction of olive tree pruning: Effect of operating conditions on solid product properties. Fuel, 202, pp. 109-117, 2017.

[21] Lu, K.M. et al., Torrefaction and low temperature carbonization of oil palm fiber and eucalyptus in nitrogen and air atmospheres. Bioresour Technol, 123, pp. 98-105, 2012.

[22] Chen, W.H. et al., Product characteristics from the torrefaction of oil palm fiber pellets in inert and oxidative atmospheres. Bioresour Technol, 199, pp. 367-374, 2016.

[23] Chen, W.H. et al., Biomass torrefaction characteristics in inert and oxidative atmospheres at various superficial velocities. Bioresour Technol, 146, pp. 152-160, 2013.

[24] Chen, W.H. et al., Non-oxidative and oxidative torrefaction characterization and SEM observations of fibrous and ligneous biomass. Appl Energy 114, pp. 104-113, 2014

[25] Uemura, Y. et al., Torrefaction of oil palm EFB in the presence of oxygen. Fuel, 103, pp. 156-160, 2013.

[26] Uemura, Y. et al., Torrefaction of oil palm kernel shell in the presence of oxygen and carbon dioxide. Fuel 144 pp. 171-179, 2015

[27] Wang, C. et al., Oxidative torrefaction of biomass residues and densification of torrefied sawdust to pellets. Bioresour Technol, 127, pp. 318-325, 2013.

[28] Rousset, P. et al., Biomass torrefaction under different oxygen concentrations and its effect on the composition of the solid by-product. J Anal Appl Pyrolysis, 96, pp. 8691, 2012.

[29] Melkior, T., Barthomeuf, C. \& Bardet, M., Inputs of solid-state NMR to evaluate and compare thermal reactivity of pine and beech woods under torrefaction conditions and modified atmosphere. Fuel, 187, pp. 250-260, 2017.

[30] ASTM D1102-84(2013). Standard Test Method for Ash in Wood. West Conshohocken, PA: ASTM Internationalhttp://dx.doi.org/10.1520/d1102 (2013).

[31] ASTM E871-82(2013). Standard Test Method for Moisture Analysis of Particulate Wood Fuels. West Conshohocken, PA: ASTM International http://dx.doi.org/10.1520/e0871 (2013).

[32] ASTM E872-82(2013). Standard Test Method for Volatile Mater in the Analysis of Particulate Wood Fuels. West Conshohocken, PA: ASTM International http://dx.doi.org/10.1520/e0872 (2013).

[33] ASTM E711-87(2004). Standard Test Method for Gross Calorific Value of RefuseDerived Fuel by the Bomb Calorimeter (Withdrawn 2004). West Conshohocken, PA: ASTM Internationalhttp://dx.doi.org/10.1520/e0711-87r04 (1987).

[34] Álvarez, A. et al., Determination of kinetic parameters for biomass combustion. Bioresour Technol, 216, pp. 36-43, 2016.

[35] Agarwal, A.K. et al., Novel Combustion Concepts for Sustainable Energy Development. 1st ed. India: Springer, 2014.

[36] Wilén, C. et al., Wood torrefaction: pilot tests and utilisation prospects. Kuopio, 2013. 